\title{
Discussion on Low Voltage Electrical Installation Technology in Building Electrical Equipment
}

\author{
Zhao Xiang ${ }^{1,}$, Yang Zhenhu ${ }^{2}$ \\ ${ }^{1,2}$ Shandong Labor Vocational and Technical College,Jinan 250022 ,China \\ azhaoxiang@126.com
}

Key words: building, electrical low voltage electrical, installation technology

\begin{abstract}
In recent years, with the rapid development of China's economy and the acceleration of urbanization, the construction industry has also developed rapidly. With the improvement of people's living standard, people have higher and better requirements for their living environment. As a result, people have higher requirements for the construction projects which are closely related to their own lives. Building electrical system is a part of construction project, and low voltage electrical installation technology is the core of building electrical technology. This technology plays an important role in ensuring the safety of electrical engineering and the quality of the whole construction project. Low voltage electrical installation has a great influence on the normal operation of building electrical equipment, and it is a very important link in the construction project. Low voltage electrical installation technology and the procedure is complicated, the quality of the finished directly affects the entire building electrical engineering operation, must be of low voltage electrical installation engineering of comprehensive control to ensure the quality of installation. This article mainly analyzes the low voltage electrical installation technology in building electrical equipment.In recent years, the development of China's construction industry is relatively rapid, in city construction, we can see is the construction of the edifice, however, with the construction industry is becoming increasingly prosperous, we have heard a lot about building the bad rumors, such as tofu engineering etc.. Therefore, improving the quality of construction is particularly important. Electrical installation in building engineering is one of the important factors that affect the quality of building. Therefore, we should improve the electrical installation technology, especially the use of a wide range of low-voltage electrical installation technology, so as to improve the quality of the entire construction project, to meet the requirements of the construction industry.
\end{abstract}

\section{Features of Low Voltage Electrical Installation Technology}

In the installation of building electrical process, will be affected by many external factors, thereby affecting its quality, there are certain hidden dangers. This requires that the installation engineers in the process of strict checks. Ensure installation quality during engineering implementation. The low voltage electrical installation works with long construction schedule, complex installation process and complicated process, which causes many external factors to be involved in the process. The quality of construction is difficult to guarantee. Before the construction, the grounding grid and pipeline laying should be adequate, and then enter the equipment test stage. At the end of all projects, the staff to debug the system to the best state, by the relevant departments testing acceptance.

\section{Construction Project Low Voltage Electrical Debugging}

When the low voltage electrical installation of building construction project is finished, it is necessary to check the operation of the components in the low voltage electrical installation project to ensure the effectiveness of the installation of low voltage electrical equipment. To be specific, the current and voltage of the set of distribution (control) equipment should be in normal condition. The motor should be electrified to observe its steering and mechanical rotation is normal, and no-load 
trial run of the motor time is 2 hours. AC motor no-load conditions continue to start two times, two times the opening time is more than 5 seconds, to ensure that the motor temperature is normal, you can start again. No-load operation, to record the current, voltage, temperature and running time and other parameters, to ensure that to achieve the electrical property requirements. After the lighting system is energized, the control of the lamp circuit should be the same as that of the distribution box circuit, and the control order of the switch and the lamp should be compared with each other.

\section{Types of Low Voltage Electrical Installation}

Installation technology of power distribution panel. The construction technology of the switchboard mainly includes the following aspects: in the cabinet, electric box and distribution panel installation process, to accurately locate the installation position. Properly connect internal wiring, make sure that the installation runs throughout the power plant. In the process of making electric cabinets, electric boxes and power distribution panels, non combustible materials should be selected to ensure firm installation and normal technical parameters. According to the drawing structure, the original distribution of the box is strictly checked, and the area is strictly divided, and the circuit interface is strictly operated according to the drawing line. To ensure the correctness of the grounding of the metal frame, the electric box and the distributor of the basic steel frame, the matching open door is provided. Make sure that the internal wiring of the cabinet, the electric box and the distributor is kept in good order and closely connected to avoid the occurrence of disorder and the occurrence of strand breaks. When choosing materials for electric cabinet, electric box and distributor, attention should be paid to the selection of flame retardant material, and the installation of the material is correct and firm, so as to ensure that the technical parameters meet the standard requirements. When installing the electric cabinet, electric box and distributor, the builders should first determine the correct and proper installation position, then correctly connect the internal wiring to ensure the safety and stability of the power equipment. The components in the electric box should be distributed according to the structure of the drawing, and the line interface and the division of each phase sequence should be operated accurately according to the drawing.

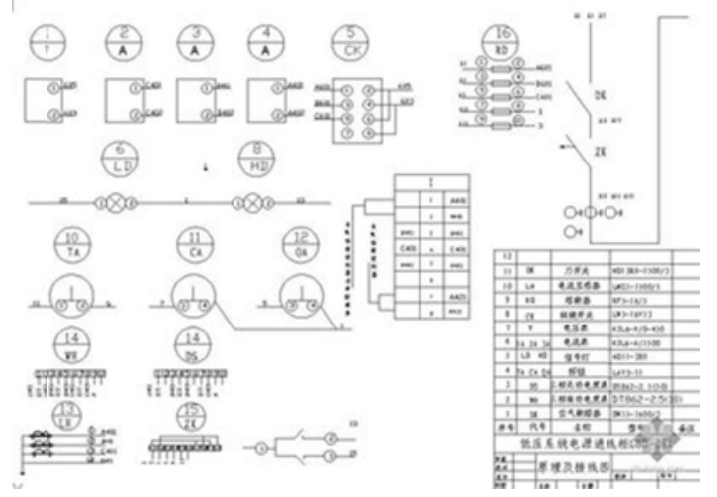

Fig.1 Installation technology of power distribution panel

Electric cabinet, electric box and wire arrangement of the switchboard shall be closely connected, and the line can not appear out of order problem, should be neat and orderly, not hurt the core wire and the wire of broken strand. The metal frame of the electric cabinet, the electric box and the Distributor shall be properly grounded and set up the corresponding open door. The metal frame and the ear thing terminal of the open able door shall be connected by bare copper wire, and a certain electric shock protection shall be set up, and the push and pull action of the distribution cabinet shall be ensured correctly.

Installation technology of pipe embedment. The important components of building electrical engineering include pipe, embedment box and welding. Pipe embedment is most important. Only by improving the quality of pipe pre embedding, the quality of building electrical engineering will be guaranteed. However, in practice, it will be affected by many factors. For example, the technical construction personnel of the technical barrier, there have been buried and buried. Therefore, the 
construction technology is also very high.

The requirements, such as the construction personnel must advance to the embedded parts specifications and drawings to strictly check the parts with embedded parts. Check whether the equipment foundation construction quality pass. For the above requirements, if the phenomenon is not up to standard, timely measures should be taken to remedy it and avoid losses. The embedded pipe and welding is an important part of low voltage electrical installation, construction personnel in operation due to different levels of technology, can sometimes lead to leakage of buried pipe or buried, some construction workers in the operation is not in accordance with the drawings and related standards were buried, all these will lead to irregular pipe pre buried. Therefore, the construction personnel in the pipe pre buried, should be strictly in accordance with construction requirements. Field staff need to carefully check the fittings according to the construction drawings of the embedded position, need the number, type and specification and other information, and pay attention to check the connection of pipes, wire box, bend radius, bend, junction box is in accordance with the relevant standard fittings. The steel pipe corrosion, welding and pipe handling shall be examined in detail and closely. Ensure that the quality of the embedded pipe meets the specifications.

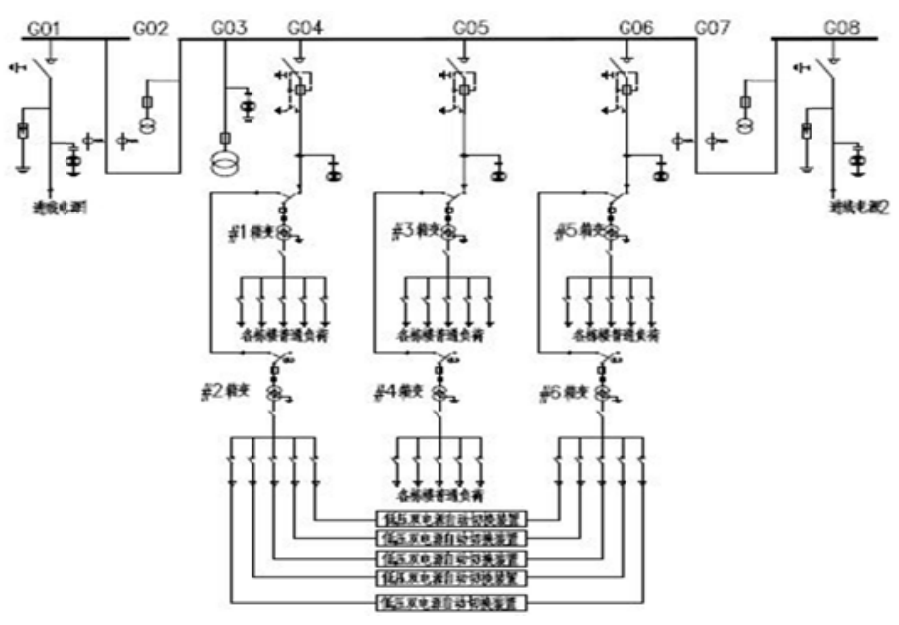

Fig.2 Installation technology of pipe embedment

Installation technology of earthing device. In the pre buried grounding line, should pay attention to in the main channel of the buried depth of the pedestrian must be over 1 meters, in order to facilitate the passage of people better and more comfortable in the pipeline above the best shop on the asphalt pavement, the. The distance between the grounding modules should not be too small, the length of the modules should be 3 to 5 times, and the buried depth should be more than $0.6 \mathrm{~mm}$. In this process, to do all the indicators of records. The installation module should be level or vertical, the contact distance should be suitable, and the lead of each module should be welded into one loop. The grounding module is the same as the trunk material. During the concealed coating operation, a fixed device shall be installed below the core line of the plastering layer, so that it can not be bent. Lay out the assembly line when exposed. Place the device as smooth as possible. Do the anticorrosion work with the paint in the welding position of the bracket. The need for building lightning protection and grounding protection, lightning protection within the building mainly is guaranteed through the installation of internal lightning protection device, internal lightning protection devices are mainly shielding facilities, equipotential connection, lightning arrester, grounding wire and other measures. These facilities can reduce lightning current and electromagnetic effects in buildings, and prevent buildings from being harmed by induced lightning and surge currents. Equipotential connection to potential metal components and systems to reduce the difference between the need of space in the lightning protection device, metal components, electrical and external conductor connected by wires, the space to form a good potential of the body. Surge protector is used for lightning protection of electronic equipment, need to be installed in the 
junction of the lightning protection division, a surge protector installed on the main switchboard, level two as the basic protection screen installed in the electrical distribution, level three is to be installed near the protection equipment in place. Besides, the earthing device should be installed to protect the personal safety and avoid the occurrence of electric shock. Grounding is a necessary measure to ensure safety, the grounding line will be laid or fixed on the support of the cable bridge, and it will be installed in the strong electricity distribution shaft. When laying down the main line for lightning protection, the depth of the trunk line should be more than one meter and the asphalt should be laid on the pipe.

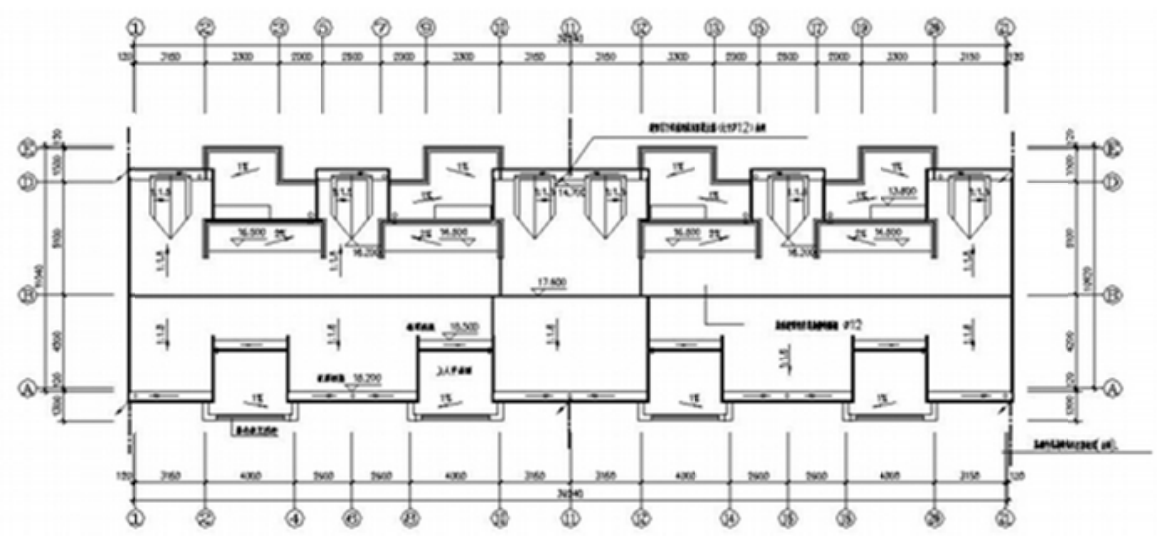

Fig.3 Installation technology of earthing device

\section{Low Voltage Electrical Installation Technical Difficulties}

The step is various and difficult to install. In order to prevent electric shock, in the power system, the neutral point and the bracket of the equipment and the electrical equipment are usually connected, and some devices which are in contact with each other are connected by a good conductor. This is the grounding technology. The grounding wire is composed of metal conductor and electrical equipment connected by the grounding body. In the installation of low voltage electrical grounding, the installation steps are various and complex, and it takes a certain amount of time. Therefore, the technical level is relatively high.

Long hours, more interference. In the construction of low voltage electrical installation, construction has a long duration, involving a wide range, a variety of processes characteristics. This will determine a lot of interference factors: wide area, cross - strong and so on. The installation process is affected by a variety of factors, and there may be a fault if there is a slight error.

Regular inspection, effective operation. In the use of low-voltage electrical process, if the insulation of electrical equipment failure, then the electric shock accident will occur, the life and property security of the vast number of employees bring great risks. In order to prevent the occurrence of such incidents, effective measures should be taken to ground. Due to the wide range of low-voltage electrical cooperation and many processes, the operation process is extremely easy to be affected by external factors, such as failures and circuit aging problemis. The construction of the highway and the afforestation of the forest will affect the transmission line. Therefore, we should regularly check, send special maintenance personnel to eliminate security risks. In general, the process of low-voltage electrical installation and use will be affected by many factors, there are many security risks, then we will strictly eliminate hidden dangers, nip in the bud, to ensure the sustainable development of low-voltage electrical.

\section{Conclusion}

In summary, through the research on the construction of low voltage electrical installation technology that has an important effect to use low-voltage electrical technology to the quality of building electrical engineering, is an important factor to guarantee the quality of the project. Low voltage electrical installation project in general is a relatively complex system engineering, 
therefore, in the construction process, we must uphold a rigorous and scientific work attitude, strict control of the quality of the project. Improve the quality of construction, and thus improve people's quality of life. This requires more attention to the quality of the project supervision work, strengthen the training of relevant personnel, supervision and inspection of the establishment of quality supervision team of practical engineering project quality, so as to promote the sustainable development and use of building electrical low-voltage electrical.

\section{References}

[1] T.Wang. Low voltage electrical installation technology in building electrical [J]. business culture, 2013, 04 (11): 38-39.(In Chinese)

[2] Z.C. Liu. Talking about low voltage electrical installations in building electrical equipment [J]. science and technology enrichment guide, 2013, 08 (14): 88-89.(In Chinese)

[3]Xu Shujie; Huang Wei; teaching reform and practice of Architectural Electrical course design; [J]; Shanxi architecture; 2008-28(In Chinese)

[4]W.Wei. Construction of electrical design principles and quality problems [J]; China's new technology and new products; 2009-08(In Chinese)

[5]Editorial department; 2009. China building electrical technology and Application Forum held in Shanghai [J]; low-voltage electrical appliances; 2009 12(In Chinese) 